\title{
A Comparative Appraisal of Some Community-Based Alternatives to Institutionalization
}

\author{
Margaret A. Rust ${ }^{1}$ \\ University of Michigan
}

\begin{abstract}
Mental disorders and criminal behavior are considered to fall under the rubric of deviance. This perspective of deviant behavior forms the framework for comparing community-based programs for emotionally disturbed persons and for offenders with institutionally based programs. The interactionist model lends itself to the development of community-based modalities in lieu of institutionalization; in contrast, the internal locus model has traditionally led to long-term confinement. In this appraisal, significant dimensions of community-based programs are explored, including selection variables for individuals, program variables, community variables, and interdependent models for assessing the interaction among them. The costs and benefits, both to the individual and to the community, of implementing community-based alternatives are discussed. Recommendations are made regarding evaluation and accountability.
\end{abstract}

It is becoming increasingly recognized that long-term institutionalization of the emotionally disturbed person and of the offender often does not serve the purpose of rehabilitation. In confinement, the person is forced to conform to the dictates of others and to adapt to a particular subculture, but the transferability of this type of learning to ordinary living situations is highly questionable.

Factors to be weighed in community versus institutional rehabilitation include the following: the types of behavior displayed by the individual, the tolerance of the community for such an individual, and the availability of alternative resources and various degrees of monitoring. In any case, the greater advantages in terms of economy, humaneness, and perhaps efficacy are leading

\footnotetext{
${ }^{1}$ Requests for reprints should be sent to Ms. Margaret A. Rust, Psychology Department, University of Michigan, Ann Arbor, Michigan 48104.
} 
to a rapid expansion of community-based programs in the fields of both mental health and corrections.

The theoretical underpinnings of a community-based approach have not been carefully delineated, and it is the purpose of this paper to identify and discuss a number of variables which should be considered in contrasting institutional and community-based programs. In this appraisal, mental disorders and criminal behavior are considered to fall under the rubric of deviance, even though admittedly the two involve different kinds of behavior, different causal factors, and different assumptive perspectives. A theoretical construct in which deviance is viewed as evolving from an interaction between the individual and the environment has important implications for community-based alternatives to institutionalization. The following aspects of community-based programs will be considered: (1) mental disorders and criminal behavior, with the interactionist model as a basis for the community-based modality; (2) significant variables and dimensions; (3) conclusions and recommendations. The significant dimensions to be examined include: selection variables for individuals, program variables, community variables, and interdependent models for assessing the interaction among them.

\section{THEORETICAL PROPOSITIONS: THE RUBRIC OF DEVLANCE}

In both mental disorders and crime, individuals display unacceptable social behavior that exceeds the norms of their community. The community has traditionally reacted with an attempt to control or punish the individual through isolation and encapsulation. The concept of the deviant career pattern has been notably explicated by Goffman (1961), who calls attention to the process of stigmatization and degradation that dramatically occurs in the act of institutionalization, with the concurrent determination of a "diagnosis," or, in effect, a public label. It has been noted that such behavior characteristics as the frequency of occurrence, the place in the hierarchy of cultural taboos, the intensity of the behavior, and the location and distribution of the behavior in the community seem to determine the intensity and duration of community recoil (Rhodes, 1972). It is clear that those with fewer resources at their disposal and with low social status are much more likely to be institutionalized and to receive solely custodial care.

The parallels in terms of society's ways of dealing with mental and criminal problems must be kept in mind when developing a conceptual framework for alternative modalities to institutionalization. Mental disorders and crime necessitate similar considerations: i.e., overlap in terms of personal problems, common kinds of treatment approaches, the relationship of the individual 
to the community, the structure and resources to be utilized, and issues regarding system processing and management vis-à-vis individual rights and priorities.

From a theoretical perspective, probably the most important aspect in contrasting mental disorders and crime are the differential assumptive bases which in turn lead to differential responses, processing, and tracking. The unique expectations in regard to the "sick" role apply to the emotionally disturbed person since society continues to view such persons from a medical framework. Being sick is distinguished from other deviant roles in that the individual is not considered responsible for his or her condition and therefore is exempted from normal social role responsibilities. The offender is assumed to have chosen to violate the rules of society; such a person is held responsible for his or her acts and is more likely to incur anger than sympathy. Since responsibility is imputed to deviant criminal behavior, punishment and imprisonment follow; when the individual is not held responsible, as with the emotionally disturbed, treatment or protective custody are in order.

\section{The Internal Locus Model}

The internal locus model has historically been applied to both mental disorders and crime and has constituted the rationale for an isolationist policy towards deviants. This model holds that the problem resides within the individual and emphasizes individual adjustment and conformity as the aims of treatment. The "mental illness" construct strongly suggests that changes in the individual's current environmental conditions will yield only superficial, shortterm effects (Sarason and Ganzer, 1968). Efforts have centered around longterm therapy for the more advantaged "mentally ill" and long-term containment in mental hospitals for the less advantaged. Similarly, in the field of corrections the onus for asocial behavior has been placed almost exclusively on the offender; the community's response has been restitution and confinement, with some effort more recently at rehabilitation of individuals.

\section{The Interactionist Model}

The interactionist model presents an alternative way of perceiving deviance. Barker (1968) held that some aspects of individual behavior can be most accurately predicted from a knowledge of the behavior characteristics of the setting rather than from the individual's behavior tendencies. Examples of the interdependence between behavior and its milieu are the patterns of behaviors enforced by physical arrangements, social forces, physiological factors, and ontward perceptions. The interactionist process, in contrast to the individual personal adjustment model, concentrates on the circumstances of the ascription 
process and regards nonconformity from the perspective of situations or actions that exceed the tolerance limits of the community, social groups, or particular individuals. Emotional problems ranging from neurosis to paranoia have been commented on in detail from an interactionist viewpoint by a variety of authors (see Spitzer and Denzin, 1968, for examples). Delinquency and crime have been explored in depth by theorists who, while proposing different etiological factors, utilize a common underlying interactionist model. (See Yinger, 1965, for a summary statement of these viewpoints.)

\section{The Community-Based Modality as a Coherent Part of the Interactionist Model}

As has been implied, the internal locus model usually leads to long-term institutionalization, both in the case of the emotionally disturbed individual and of the juvenile delinquent or adult criminal. Concurrently, rehabilitation resources, which can now feasibly be made available only to a segment of the institutionalized, are funneled into a limited number of vocational training programs and treatment programs, the latter in particular designed to reinforce conventional norms. The community-based modality, construed as an intensive intervention effort in lieu of institutionalization and involving community as well as individual change, is usually not the preferred recourse within the internal locus model.

In contrast, the community-based alternative to institutionalization does present itself as an optimal choice point within the interactionist model. The interactionist model provides for a continuum of responses to deviants, ranging from "no treatment" to short-term institutionalization; however, it now appears that community-based programs of varying intensity such as day treatment, group living facilities, outpatient care, and probation are the most promising ways of dealing with the majority of individuals who pose problems to the community.

It will be important, therefore, when exploring various programs to attend to the degree of their integration with the community and the extent to which they attempt to alter stress variables in the community. Community-based alternatives should incorporate the following emphases: (1) return of the individual within a relatively short period of time to living in the community at a level of functioning which is acceptable to him or her and to the community; (2) a 2-pronged approach of working with the individual and with the immediate neighborhood to achieve this goal; (3) a diminution of the stigmatizing process and crystallization of the deviant behavior. Community-based alternatives are thus construed to operate within the entire range of intervention levels; i.e., primary, secondary, and tertiary. 


\section{SIGNIFICANT VARIABLES AND DIMENSIONS IN COMMUNITY-BASED PROGRAMS}

Individual selection variables, program variables, and community variables appear to be the most critical to consider when designing and operating mental health and correctional community-based programs. These factors interact with each other, and the decisions made with regard to the particular mix should be predictive of the degree of success of a program. In order to arrive at some substantive generalizations based on comparing data available on communitybased programs, this analysis has been delimited to the following four modalities common to the areas of corrections and mental disorders: residential centers, group homes, halfway houses, and day treatment centers. These four modalities constitute decremental degrees of closeness and monitoring, but each is seen as entailing substantial involvement with the client in a community-based setting in lieu of such involvement in an institutionally based setting. In addition to the criterion of substantial involvement in the community by its clientele, a community-based program must meet the criterion of promoting considerable contact between clientele and community people, thus minimizing restrictions of the flow in and out of the facility.

In examining the critical variables and dimensions necessary to construct a viable community-based program, emphasis will be placed on experimental and innovative programs which illustrate some of the varying components in the range of types of community-based approaches.

\section{Selection Variables for Individuals}

Criterion measures for selection of individual participants vary widely. The selection process is, of course, interlocked with the other two variables, the programmatic structure and the community context. The following three criteria for determining the eligibility of individuals for an intensive community-based program (Rachin, 1972) are suggested: (1) having problems in an intermediary range, i.e., those that are not so serious that highly structured programming and security measures are needed and, on the other hand, those that do not stem merely from a poor home situation, in which case a foster home placement would suffice; (2) having some capacity for participating in a confrontative examination of day-to-day behavior, expressing some interest in doing so, and conceding that others may be able to understand one's problems; (3) having some ability to cope with daily, unsupervised community living. However, clinical impressions, offense data, or a history of past inabilities should not necessarily be considered sufficient indices with which to conclude that a person cannot cope in a community program. 
It appears that several programs are effectively handling individuals who would ordinarily be automatically assigned to institutional programs. For example, the Community-Care Home, a coed halfway house for young adults who temporarily require intensive care (Rehabilitation Mental Health Services, 1971), is designed to serve a population usually excluded from community-based facilities; almost all the residents are acutely ill psychotics and neurotics, 85 per cent of whom would be classified as schizophrenics. Other programs that are effectively handling institutional candidates include Day top Lodge, a residential treatment facility for male addicts which utilizes the "therapeutic community" model combined with gradual reintegration with the larger community (Shelly \& Bassin, 1964); Fairclough's Halfway Houses, supportive residential rehabilitation centers for indigent male alcoholics (Fairclough, 1971); Criswell House, a halfway house for seriously delinquent males (Flackett \& Flackett, 1970); and the California Youth Authority's Community Treatment Program, a form of augmented parole consisting of some form of daily day program, often used in conjunction with expanded resources such as family treatment or group home placement (Stark, 1967).

It would seem that exclusionary criteria are most appropriately based on the design and goals of the program/facility and on the tolerance and resource level of the particular community. The evaluative-oriented attempts of the California Youth Authority to develop a classificatory schema of interpersonal maturity levels that can be correlated with delinquent behavioral styles is functional because it can be linked to a typology of treatment designs. The interpersonal maturity level schema is also useful in matching types of individuals and problems along a continuum of openness versus closedness in respect to community programs. (See California Youth Authority, 1971, for further research on individual selection variables.)

\section{Program Variables}

The extent to which programs can incorporate a broader age range, provide for coed facilities, and expand in size without acquiring bureaucratic characteristics are variables which are in flux at the moment. $A$ priori assumptions about these variables need to be reconsidered.

A crucial intermediary goal for all community-based programs is the maintenance of individuals in the program; such maintenance involves modification of objectionable behaviors of participants and offering a viable program that will hold their interest. Another intermediary goal is maintaining the program itself, an aspect that necessitates a continuing process of raising funds and soliciting community support. Long-range goals extend from preparing the individual to perform a functional role in society with minimal stigma to providing an intervention service at a considerable reduction of cost. Some programs such as Probation Offenders Rehabilitation Training, better known as PORT, a commu- 
nity-directed residential treatment program serving a wide age-range of juvenile and adult males (Schoen, 1972), and Fairclough's houses focus primarily on helping participants to acquire vocational skills and to become integrated into a local school or employment situation while they are in the program. These types of programs were reportedly the most effective in respect to recidivism rates and in respect to acceptance by both the community and the participants, because they facilitated the legitimization of the individual in the community through his or her performance of an economically viable role. A somewhat different approach is simply to aid participants to establish "credit" for completion of the program, which usually incorporates graduated levels of responsibility, this in itself being viewed as an achievement which will affect the neighborhood's perception of the deviant individual. Attaining this goal, however, necessitates the building of good relationships with the court, the police, and local residents. As can be seen, all these goals place some priority on altering the community's perception of the individual as deviant and/or increasing its tolerance of a wider range of behaviors.

As a preventive function, two important elements that figure in the broad perspective of effectiveness are the ease with which the facility may be contacted by potential clients and the availability of aftercare services. Of particular note in regard to openness and variety of options is the Manhattan Project, which operates both as a halfway house and a day program and serves psychiatric referrals, adult probationers and parolees, and juvenile delinquents (Keller \& Alper, 1970).

In general, residental centers seem to be limited in their capacity to provide follow-up services, although a few encourage persons to return for house meetings. Day programs, probably because of their original design as a transitional device for mental patients and prison inmates, usually offer a wider continuum of partial day care and sheltered workshops, as well as intensive day treatment (see Bonn, 1972, re the Fort Logan Mental Health Center Day Care Programs).

An assessment of the treatment methods employed by programs is a difficult and debated area. Several treatment techniques seem to be efficacious, at least when paired with specified kinds of clientele. In the programs reviewed, behavior modification techniques were very useful in creating a consistent structure in which staff and clients could work with a minimum of conflict and confusion; when provision was made for gradational levels in which realistic social and economic reinforcers were utilized, the token economy facilitated the shaping of specific behaviors and pointed the way to clear-cut routes of achievement and status. Maintenance of desired behaviors was best ensured when provision was made for a "senior" level in which the client was in effect no longer on the token system; i.e., his or her actions were not closely monitored and ordinary reinforcers were used that would obtain in the community situation to which the person would return. 
Guide group interaction (GGl), an approach that attempts to make the group both the target and the medium of change, has worked well in programs for the motionally disturbed, for drug addicts, and for offenders. Criswell House, previously mentioned, is a prototype of the GGI model, with compulsory 90-minute GGI sessions being held five evenings a week and with the boys eating, working, and living together in small teams.

Several programs, such as the Community-Care Home, already described, have found a reality-oriented life-management approach to be effective. One would suspect that the emphasis on group and individual planning is particularly helpful for those with emotional problems and those who have difficulty coping with daily tasks and setting goals. Psychodynamic treatment and transactional analysis seemingly have some utility in fostering self-understanding and a reflective attitude toward behavior for persons who feel conflicted about their behavior. The family-centered model and the therapeutic community model were helpful to immature, dependent youth and to persons who needed a warm, intimate setting with interactive direction from staff members and residents. Most programs utilized some combination of these change modalities; behavior modification, group sessions, and a reality-oriented approach were the most frequently employed. About six programs were encounterd which had viable experimental components.

The 5-year study at Dayton Lodge, proposes to involve a minimum of 100 drug addicts who are to be compared to a group of addicts on regular probation supervision; criterion measures are the rate of return to drug use after leaving the program and changes in values and self-identity as measured by the Hill-Monroe Inventory. A promising evaluation plan is being implemented by Family Group Homes for Youth, Inc., serving emotionally disturbed and delinquent male and female youth (Reed, 1973); a computerized data bank of initial information on each youth is being assembled that will then serve as a baseline for periodic subsequent analyses of the functioning of the individual.

In the area of corrections, the Silverlake Experiment (Empey \& Lubeck, 1971), which compared a community-based GGI residential center with a traditional institution for delinquents, is noteworthy because of the carefully designed theoretical model, the detailed analysis of recidivism and financial personal costs, and the computerized simulation model. The recidivism rates of the two programs were approximately the same, but the differential in terms of financial costs is impressive. The cost of the community program was about $40 \%$ that of the institutional program when one takes into account that the average length of stay for the former was about half that of the institutional program. While most community-based programs do operate on a considerably lower budget than do institutional programs, a few programs have equivalent or even higher financial costs, primarily because of specialized remedial or vocational training programs, or because of heavy emphasis on the employment of treatment personnel. A sophisticated economic analysis must also take into account the not-so-apparent 
costs that are assumed by the community itself, as for example, the provision of special services in the community schools, the provision of vocational rehabilitation counseling and training, and the utilization of family members in a caretaking function when the individual is spending time at home. Other programs with comprehensive evaluation studies include PORT, Criswell House, and Provo, an experimental day program for delinquent boys which was compared to an incarcerated control group and a regular probation control group (Empey \& Erickson, 1972).

\section{Community Variables}

The locus of the interactionist approach is the function of the person in the setting; the community itself must be considered as the setting since community-based programs by definition have permeable boundaries with the environment and since the individual must function in the surrounding neighborhood as well as in the program. With much less attention being paid to community variables in comparison to individual or program variables, the importance of community variables continues to be underestimated. Administrators familiar with the internal locus model often attempt to implant self-contained units in the community, thus defeating the objectives of the community-based approach. Another common error is the lack of an epidemiological and attitudinal assessment of the community. Only the California Youth Authority, which has charge of all delinquent youth in both community and institutional programs (Warren, 1972), and Crofton House, a halfway house for adult male offenders who would ordinarily be assigned to a rural camp setting (D. C. Dept. of Corrections, 1971) appeared to be conducting research that had as one of its experimental components the analysis of the program's interaction with the particular community.

The impressionistic consensus among writers in both fields is that the sites that meet with the least community resistance and that provide an environment in which participants can most easily interact are those located in heterogeneous or transitional neighborhoods. A racially, culturally, and economically diverse community is advantageous to a mixed population (Linsky, 1970). The ecological and structural aspects of a facility will determine its opportunities and its limits. Thus the accessibility of public transportation, of shops, of schools and jobs, and of recreational opportunities will help to form the program (Criswell House, PORT).

The size and the visibility of the facility, in combination with the kinds of problems of the residents or clients, must be considered when attempting not to overwhelm a community. It is important that the facility blend architecturally with the surrounding neighborhood, and that the physical interior not resemble that of the typical institution - factors many programs frequently overlooked.

Extensive community organization efforts are recommended in planning programs, both to alleviate community fears (especially in a homogeneous or a 
cohesive community) and to set up links with community resources. A careful assessment of the community's probable reaction is needed, with allowance of six months to one year to meet with community agencies and to organize a steering committee of local and indigenous leaders. Many community programs have failed because they have not gained the cooperation of those community elements essential to their operation; i.e., the criminal justice system, schools, employers, businessmen, and rehabilitative agencies. The consensus of most programs is that the schools tend to be the most inflexible community agency and are typically ready to expel students who do not conform to a fairly narrow range of expectations. Usually, long-term efforts have to be made to provide for a more relevant classroom situation and to gain the cooperation of the local school. A few community programs have gained outstanding community support through reliance on indigenous community residents for administration and staffing. A public relations feature that more programs should consider is the establishment of some type of business that would be staffed by clientele and would facilitate normal contact with a large cross-section of the neighborhood.

\section{Interdependent Models}

Theorists differ about the extent to which they perceive the entire community as the focal point of intervention, but at the very least it is necessary to concede that the most carefully constructed treatment or change plan will have little long-range effect if some incentives for new behaviors are not forthcoming from the environment. Taking an interactionist perspective requires that one attempt to work more intensively with target individuals in the community, both those seen as leaders and those seen as deviants, as well as attempt to work for immediate and long-range changes in the community. Much more study needs to be done in regard to the interaction among community variables, program variables, and individual variables. Theoretical models which take into account the interdependent nature of individual, programmatic, and community variables seem to have the most potential for those designing programs and conducting research in the community (refer to theories developed by Sterns et al., 1956, and Kelly, 1966).

\section{DISCUSSION AND CONCLUSIONS}

In considering the implementation of community-based programs, the specific costs and benefits to the individual and to the community must be weighed. Community-based alternatives imply a diffusion of the dichotomous classification of normal versus deviant and a beakdown of the boundaries of the traditional legal and mental health deviance management systems; more pressure is thus placed on the community to accept responsibility and to develop coping resources. Although community residents would normally be expected to utilize 
community resorces, participants in intensive community treatment programs will most likely need to make use of particular community resources (schools, employment agencies, recreation centers) in ways that may require additional deployment of energy and time. Thus cost factors, as previously mentioned, may be entailed in the modification and expansion of community resources.

The community is legitimately concerned about the loss of coercive restraint over the deviant individual and the threat he or she poses to community safety. Some discretion must, of course, be used; i.e., the containment of individuals who need firm controls for a time-limited period may be necessary. However, it has been demonstrated that the majority of emotionally disturbed persons or offenders will not present a serious threat to the community if placed in appropriate community programs.

Juxtaposed to these possible cost factors to the community are the benefits that may accrue to the community. The economic cost of containment in community-based programs of all types has in general been less than institutional containment; this is combined with the advantage of a much shorter average period of stay. Economic advantages also figure in the shortening and lessening of the interruption of the functional role of the individual, especially in respect to the adult who is the wage-earner or the caretaker of a family. Some states are beginning to return these savings to the community by passing legislation whereby the state reimburses communities to the extent that their use of mental hospitals, prisons, and institutions for delinquents is reduced. The literature reflects a growing interest in cost-benefit analysis as a means of determining more systematically which procedures actually "succeed" in terms of return on funds invested. The use of new correctional "costs", rather than recidivism rates, is beginning to be taken as a primary index of adjustment in the community. The hope is that further applications of these cost-benefit techniques may be used to achieve optimal performance of the system as a whole.

The costs to the individual seem to consist chiefly of less structural supports available and more subjection to community stress. A communitybased facility by definition cannot offer 24-hours supervision, built-in controls, or the degree of structured programming that an institution can. Neither can it provide the removal from the community, family, or situational stress which an individual may need for at least a short period of time in order to reassess his or her situation at an optimal rate. There may be fewer opportunities for specialized training in a community-based program; an individual who needs a particular kind of remedial education or occupational therapy may be able to find these programs better developed in certain institutions than in the immediate community.

Attention has already been given to the benefits that accrue to the individual in terms of the lessening of self-devaluation, of stigma, and of role interruption in regard to work, school, family, and friends. The personal development of the individual and the formation of positive habits seem more likely to occur 
in a community-based program because it is closer to an ordinary living situation (with the exception of such cases as are mentioned above).

The current trend is toward the acceptance and implementation of the concept of handling the emotionally disturbed and the offender in the community. From the foregoing appraisal, it appears clear that a large number of those who are candidates for institutionalization may instead be retained in the community as safely, as effectively, and at much less expense to both the individual and the public, provided that such programs are carefully planned to link with community resources. The observed effects of the overcrowded and isolated institution on the personality and social adaptation of the incarcerated individual are avoided. In general, community-based programs constitute a much more humane and natural environment than institutions. However, until alternatives to institutionalization can be shown to be more clearly effective than incarceration in preventing further mental disorders and crime, the reduction of correctional costs, economic and psychological, will remain a major rationale for handling institutional candidates in the community.

One would suspect that a major obstacle to the wider development and use of community alternatives in both mental disorders and juvenile and adult corrections will contine to be the widespread rejection of such persons by the community itself and the desire on the part of society to disassociate itself from those who are seen as stigmatized. The fate of community alternatives may well rest on the issue of whether the task of "social" control will be relegated to a progressively smaller proportion of the societal body, with the majority of society refusing responsibility for an increasing variety of behaviors and persons, or whether communities will work toward retaining or reabsorbing the deviant individual into the life of the community.

\section{RECOMMENDATIONS}

The task of reintegration of the emotionally disturbed person or the offender involves developing or reconstruction ties between the person and the communitv. Although concentration on helping the individual to develop linkages with the existing community resource channels is critical, often it will be just as important to consider creating new community resources and new, alternative life settings. These alternative settings may extend to living situations, work settings, and social settings.

Given the current expansion in the numbers and variety of communitybased programs, it becomes even more crucial that accountability and evaluation components become a salient part of the community-based model. While it is neither feasible nor desirable for all programs to have an experimental design, certainly many programs would circumvent difficulties if more consideration were given, especially in the initial planning phase, to the individual, program, 
and community variables that have been delineated here. At the least, some simple measures of the individual behavioral objectives, cost-benefit rates, and community opinions should be taken so that feedback has a systematic input into the program, the public served, and the funding sources. The most efficient model may be one whereby funding sources to agencies or programs are made contingent upon their achieving specific goals, with all clients having the option of contracting services from a range of agencies. Evaluation should be oriented toward refining interdependent models of interaction among individual, community, and program variables with the goal of developing more efficient, more effective, and more innovative alternatives to institutionalization.

\section{REFERENCES}

Barker, R. Ecological psychology: Concepts and methods for studying the environment of human behavior. Stanford: Stanford University Press, 1968.

Bonn, E. Day care: A vital link in services. Hospital and Community Psychiatry, 1972, 23(5), 157-159.

California Youth Authority. The status of current research in the California youth authority. CYA's Annual Report, 1971.

D. C. Department of Corrections. Summary of completed research: 1970-1971. Report \#2, 1971.

Empey, L., \& Erickson, M. The Provo Experiement: Evaluating community control of delinquency. Lexington, Mass.: D. C. Heath \& Co., 1972.

Empey, L., \& Lubeck, S. The Silverlake Experiment: Testing delinquency theory and cornmunity intervention. Chicago: Aldine Publishing Co., 1971.

Fairclough, P. Supportive residential treatment of indigent male alcoholics. Journal of Drug Issues, 1971,1 (2), 160-165.

Flackett, J., \& Flackett, G. Criswell House: An alternative to institutional commitment for the juvenile offender. Federal Probation, 1970, 34(4), 30-37.

Goffman, E. Asylums: Essays on a social situation of mental patients and other inmates. Garden City, N. Y.: Anchor Books, 1961.

Keller, O., \& Alper, B. Halfway house: Community-centered correction and treatment. Lexington, Mass.: D. C. Heath \& Co., 1970.

Kelly, J. Ecological constraints on mental health services. American Psychologist, 1966, 21, $6,535-539$.

Linsky, A. Community homogeneity and exclusion of the mentally ill: Rejection vs. consensus about deviants. Journal of Health and Social Behavior, 1970, 11(4), 304-311.

Rachin, R. So you want to open a halfway house. Federal Probation, 1972, 36(1), 30-37.

Reed, R. Unpublished reports on Family Group Homes for Youth, Inc. National assessment of juvenile corrections. University of Michigan Ann Arbor.

Rehabilitation Mental Health Services, Inc. Rehabilitating patients in the community. Hospital and Community Psychiatry, 1971, 22(10), 306-309.

Rhodes, W. Behavioral threat and community response: $A$ community psychology inquiry. New York: Behavioral Publications, 1972.

Sarason, I., \& Ganzer, V. Concerning the medical model. American Psychologist, 1968, $23(7), 507-510$.

Schoen, K. PORT: A new concept of community-based correction. Federal Probation, $1972,36(3), 35-40$.

Shelly, J., \& Bassin, A. Daytop Lodge: Halfway house for drug additcs, Federal Probation, $1964,27(4), 45-54$.

Spitzer, S., \& Denzin, N. (Eds.) The mental patient: Studies in the sociology of deviance. New York: McGraw-Hill, 1968. 
Stark, H. Alternatives to institutionalization. Crime and Delinquency. 1967, 13(2), 323-326.

Sterns, G., Stein, M., \& Bloom, B. Methods in personality assessment. Glencoe: The Free Press, 1956.

Warren, M. Correctional treatment in community settings: $A$ report of current research. Rockville: NIMH, 1972.

Yinger, J. Toward a field theory of behavior: Personality and social structure. New York: McGraw-Hill, 1965. 